Gut, 1986, 27, 844-848

\title{
Plasma arginine in cancer of the gastrointestinal tract: effect of surgical treatment
}

\author{
R E GLASS, A W GOODE, B J HOUGHTON, AND L W ROWELL \\ From the Professorial Surgical Unit and Department of Chemical Pathology, The London Hospital, London
}

SUMmaRY The concentration of 21 amino acids was measured in the venous plasma of 41 patients with cancer of the gastrointestinal tract who had lost weight, 12 patients who had lost a similar amount of weight from non-malignant, non-septic conditions (benign weight loss), 12 patients with cancer of the gastrointestinal tract who had not lost weight and 21 control patients. Sixteen patients with localised tumours were restudied eight and 12 weeks after successful removal of the primary growth. Six patients with pyloric stenosis (benign weight loss) were similarly studied for comparison after corrective surgery. The concentration of the amino acid arginine was significantly greater in patients with cancer both with weight loss $(71 \cdot 2 \pm 4 \cdot 1 \mu \mathrm{mol} / \mathrm{l}$ mean \pm SEM $)$ and without weight loss $(66 \cdot 8 \pm 4 \cdot 1 \mu \mathrm{mol} / \mathrm{l})$ when compared both with patients with benign weight loss $(34.6 \pm 3.2 \mu \mathrm{mol} / \mathrm{l})$ and with control patients $(48.2 \pm 3.5 \mu \mathrm{mol} / \mathrm{l})(\mathrm{p}<0.05)$. In patients with cancer subjected to surgery the concentration of arginine $(76 \cdot 4 \pm 7 \cdot 5 \mu \mathrm{mol} / \mathrm{l})$ fell to normal levels eight weeks after operation and remained normal 12 weeks after surgery $(48.6 \pm 4.4 \mu \mathrm{mol} / \mathrm{l})(\mathrm{p}<0.05)$. This was in contrast with the rise in plasma arginine in patients with pyloric stenosis after surgery, suggesting that the raised level of arginine was due to the presence of the primary tumour.

Patients with tumours of the gastrointestinal tract usually lose weight. Whether this is because of reduced dietary intake or specific metabolic changes induced in the host by the presence of the tumour is a subject of debate.

Clarke et $a l^{1}$ in a study of amino acid levels in peripheral venous blood showed that patients with cancer and weight loss had amino acid patterns that were significantly different from patients who were malnourished for other reasons. Patients in this study were, however, suffering from a variety of neoplastic conditions, including cancer of the lung, breast, and lymphoreticular system.

The aim of the present study was to measure plasma amino acid profiles in patients with staged cancers of the gastrointestinal tract; to attempt to relate possible changes in amino acid concentration to loss of weight and to note the effect of surgical removal of the tumour. Comparisons were made with a group of normal adult subjects and with a group of malnourished patients, but without evi-

Address for correspondence: Mr R E Glass. MS, FRCS. The London Hospital, Whitechapel, London E1 1BB.

Received for publication 11 October 1986 dence of malignant disease. Patients with pyloric stenosis from peptic ulcer were included in the malnourished group and were similarly studied after corrective surgery.

\section{Methods}

\section{PATIENTS}

Fifty three patients (34 men and 19 women) with cancer of the gastrointestinal tract were studied; three with squamous cell carcinoma of the oesophagus, 18 with adenocarcinoma of the stomach and 32 with adenocarcinoma of the rectum or colon. Of this group 41 patients had lost weight.

Twelve patients (seven men and five women) who had lost weight from non-malignant, non-septic conditions were studied for comparison; six with pyloric stenosis from peptic ulcer, two with a short bowel from previous small bowel resection, and four who had lost weight with psychological anorexia. Twenty one patients admitted for elective treatment of non-malignant and minor surgical conditions were studied as controls.

In those patients with malignant disease the extent of spread of the tumour was assessed from 
the findings at laparotomy and histological examination of the specimens removed. Of 53 patients with malignant disease 34 had tumours removed with the prospect of cure in that there was no evidence of metastases or residual tumour at surgery.

A group of 16 patients was restudied eight and 12 weeks after successful removal of the primary tumour; one with cancer of the oesophagus, two with cancer of the stomach and 14 with cancer of the colon or rectum. The growth was confined to the bowel in two patients, had spread outside the bowel in 14 patients, of which eight had tumours that had spread into local lymph glands. Six patients with pyloric stenosis from peptic ulceration were similarly studied after surgery.

\section{AMINO ACID ANALYSIS}

A sample of venous blood was taken after an overnight fast with the patient rested in bed. The plasma was separated by centrifugation. The concentration of 21 amino acids in the venous plasma was measured with a Locarte Amino Acid Analyser with an internal standard of norleucine (Sigma Chemical Co).

\section{ANTHROPOMORPHIC ASSESSMENT}

The fat mass and lean body mass in those patients who had lost weight was estimated with Harpenden skin fold calipers. ${ }^{2}$ There is a close correlation between fat free mass and lean body mass, as measured by total body potassium ${ }^{3}$ and fat free mass was taken to represent lean body mass in each subject.

The pre-illness weight of each patient and length of disease in weeks was recorded at patient interview. The height of the patient, their age, and preillness weight were substituted in the regression equations of Goode and Hawkins ${ }^{3}$ to predict the pre-illness lean body mass in each subject. Preillness fat mass was taken to be the difference between predicted lean body mass and the preillness weight. The difference between pre-illness and present total weight, lean body mass and fat mass was expressed as percentage change, and from the duration the rate of change calculated and expressed as percentage change per week.

\section{STATISTICAL METHODS}

The statistical method used to compare the concentration of amino acids in the various groups of patients was a one-way analysis of variance using logs of the data when the distribution was positively skewed. In addition, the Student-Newman-Keuls procedure was used to adjust for making multiple comparisons between groups.

Further comparisons of amino acid concentration before and after operation were made using the Wilcoxon's rank sign test, and when paired data was available the Wilcoxon's signed rank test. If there were fewer than seven pairs for comparison a paired $t$ test was used.

\section{Results}

Table 1 shows the mean concentration of each amino acid estimated in 41 patients with cancer who had lost weight, 12 patients with cancer who had not lost weight, 12 patients who had lost weight with non-malignant conditions (benign weight loss) and 21 control patients. Although there were differences in the concentration of certain amino acids in these groups of patients, these differences only reach statistical significance with respect to alanine, threonine, taurine, methionine, leucine, and arginine.

The concentration of the amino acid arginine was significantly higher in patients with cancer both with weight loss $(71 \cdot 2 \pm 4 \cdot 1 \mu \mathrm{mol} / \mathrm{l})$ and without weight loss $(66 \cdot 8 \pm 4 \cdot 1 \mu \mathrm{mol} / \mathrm{l})$ when compared with patients with benign weight loss $(34 \cdot 6 \pm 3 \cdot 2 \mu \mathrm{mol} / \mathrm{l})$, and with control patients $(48 \cdot 2 \pm 3.5 \mu \mathrm{mol} / \mathrm{l})(\mathrm{p}<0 \cdot 05)$. The concentration of the amino acids alanine, taurine, and methionine was significantly lower in patients with cancer and weight loss when compared with control patients $(p<0 \cdot 05)$. The concentration of leucine and threonine was significantly lower in patients with benign weight loss when compared with control patients $(\mathrm{p}<0.05)$. In this group of patients the concentration of arginine in the plasma appeared to distinguish those patients who had lost weight from cancer of the gastrointestinal tract $(71 \cdot 2 \pm 4 \cdot 1 \mu \mathrm{mol} / \mathrm{l})$ from those patients who had lost weight from non-malignant conditions $(34 \cdot 6 \pm 3 \cdot 2 \mu \mathrm{mol} / \mathrm{l}) \quad(\mathrm{p}<0 \cdot 001)$.

The concentration of arginine in the plasma of patient with cancer did not appear related to the extent of spread of the tumour, and was lower in patients with evidence of metastasis $(65.9 \pm 4 \cdot 6$ $\mu \mathrm{mol} / \mathrm{l})$ when compared with patients with localised tumours $(72.7 \pm 4 \cdot 6 \mu \mathrm{mol} / \mathrm{l})$.

Table 2 shows the mean per cent change and the mean per cent change per week of total weight, lean body mass and fat mass estimated in those patients with malignant weight loss and in those patients with benign weight loss. Those patients with cancer who had lost weight appeared to have lost a similar amount of weight $(15 \cdot 1 \pm 1 \cdot 6 \%)$ as those patients with benign weight loss $(14 \cdot 4 \pm 2 \cdot 1 \%)$. In addition, the relative amount of fat loss to lean body mass loss in both groups of patients did not show any significant difference in either total loss or compositional loss. The concentration of arginine measured 
Table 1 Plasma concentration of amino acids ( $\mu \mathrm{mol} / \mathrm{l}$, mean $\pm S E M)$ in 12 patients with benign weight loss, 21 control patients, 12 patients with cancer who had not lost weight, and 41 patients with cancer and weight loss. Square brackets indicate significant differences between groups $(p<0 \cdot 05)$

\begin{tabular}{|c|c|c|c|}
\hline $\begin{array}{l}\text { Benign } \\
\text { weight loss }\end{array}$ & Controls & $\begin{array}{l}\text { Cancer no } \\
\text { weight loss }\end{array}$ & $\begin{array}{l}\text { Cancer } \\
\text { weight loss }\end{array}$ \\
\hline \multicolumn{4}{|l|}{ Taurine } \\
\hline \multirow[t]{2}{*}{$91.8 \pm 8.8$} & $106 \cdot 7 \pm 8 \cdot 0$ & $116 \cdot 5 \pm 22 \cdot 4$ & $\underset{79 \cdot 2 \pm 5 \cdot 5}{ }$ \\
\hline & & & $ـ$ \\
\hline \multicolumn{4}{|l|}{ Aspartate } \\
\hline $19 \cdot 7 \pm 5 \cdot()$ & $16 \cdot 0 \pm 3 \cdot 0$ & $14 \cdot 8 \pm 3 \cdot 7$ & $12 \cdot 2 \pm 1 \cdot 7$ \\
\hline \multicolumn{4}{|l|}{ Threonine } \\
\hline $76 \cdot 4 \pm 6 \cdot 5$ & $136 \cdot 2 \pm 10 \cdot 2$ & $119 \cdot 8 \pm 7 \cdot 7$ & $114 \cdot 6 \pm 6 \cdot 9$ \\
\hline \multicolumn{4}{|c|}{ - } \\
\hline \multicolumn{4}{|r|}{ 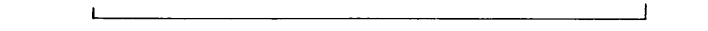 } \\
\hline \multicolumn{4}{|l|}{ Serine } \\
\hline $102 \cdot 4 \pm 10 \cdot 3$ & $130 \cdot 9 \pm 8 \cdot 9$ & $120 \cdot 3 \pm 7 \cdot 4$ & $114 \cdot() \pm 5 \cdot()$ \\
\hline \multicolumn{4}{|l|}{ Asparagine } \\
\hline $37 \cdot 7 \pm 5 \cdot 4$ & $47 \cdot 1 \pm 2 \cdot 7$ & $42 \cdot 5 \pm 3 \cdot 2$ & $39 \cdot 4 \pm 1 \cdot 5$ \\
\hline \multicolumn{4}{|l|}{ Glutamic acid } \\
\hline $131 \cdot 1 \pm 20 \cdot 7$ & $103 \cdot 9 \pm 12 \cdot 4$ & $120 \cdot 7 \pm 22 \cdot 4$ & $86 \cdot 3 \pm 8 \cdot 4$ \\
\hline \multicolumn{4}{|l|}{ Glutamine } \\
\hline $355 \cdot 6 \pm 34 \cdot 2$ & $425 \cdot 0 \pm 25 \cdot 2$ & $394 \cdot 9 \pm 26 \cdot 7$ & $4(0) 3 \cdot 7 \pm 17 \cdot 2$ \\
\hline \multicolumn{4}{|l|}{ Glycine } \\
\hline $287 \cdot 9 \pm 29 \cdot 2$ & $299 \cdot 1 \pm 23 \cdot 2$ & $239 \cdot 4 \pm 22 \cdot 6$ & $231 \cdot 2 \pm 12 \cdot 0$ \\
\hline \multicolumn{4}{|l|}{ Alanine } \\
\hline $361 \cdot 9 \pm 4() \cdot 4$ & $395 \cdot 5 \pm 22 \cdot 4$ & $354 \cdot() \pm 17 \cdot 2$ & $306 \cdot 3 \pm 16 \cdot 8$ \\
\hline \multicolumn{4}{|l|}{ Citruline } \\
\hline $34 \cdot 2 \pm 6 \cdot 1$ & $39 \cdot 4+2 \cdot 7$ & $56 \cdot 3 \pm 7 \cdot 1$ & $48 \cdot 5 \pm 2 \cdot 8$ \\
\hline \multicolumn{4}{|l|}{ Valine } \\
\hline $215 \cdot 9 \pm 23 \cdot 6$ & $246 \cdot 6 \pm 13 \cdot 6$ & $213 \cdot 6 \pm 16 \cdot 1$ & $203 \cdot 2 \pm 12 \cdot 4$ \\
\hline \multicolumn{4}{|l|}{ Cystine } \\
\hline $34 \cdot 5 \pm 5 \cdot 2$ & $57 \cdot 2 \pm 3 \cdot 4$ & $49 \cdot 5 \pm 3 \cdot()$ & $53 \cdot 6 \pm 2 \cdot 2$ \\
\hline \multicolumn{4}{|l|}{ Methionine } \\
\hline $27 \cdot 4 \pm 2 \cdot 4$ & $30 \cdot 1 \pm 1 \cdot 5$ & $26 \cdot 6 \pm 1 \cdot 2$ & $24 \cdot 0 \pm(0 \cdot 9$ \\
\hline \multicolumn{4}{|l|}{ Isoleucine } \\
\hline $73 \cdot 6 \pm 8 \cdot 8$ & $68 \cdot 6 \pm 2 \cdot 6$ & $75 \cdot 1 \pm 4 \cdot 9$ & $70 \cdot 5 \pm 3.5$ \\
\hline \multicolumn{4}{|l|}{ Leucine } \\
\hline $112 \cdot 5 \pm 12 \cdot 1$ & $137 \cdot 5 \pm 5 \cdot 6$ & 14()$\cdot 7 \pm 12 \cdot 0$ & $124 \cdot 2 \pm 6 \cdot 4$ \\
\hline & 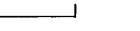 & \\
\hline \multicolumn{3}{|l|}{ Tyrosine } & $62 \cdot 0 \pm 3 \cdot 0$ \\
\hline \multicolumn{3}{|l|}{ Phenylalanine } & $62 \cdot 3 \pm 2 \cdot 4$ \\
\hline Ornithine & & & \\
\hline $110 \cdot 2 \pm 11 \cdot 2$ & $144 \cdot 1 \pm 10 \cdot 2$ & $151 \cdot 3 \pm 20 \cdot 1$ & $113 \cdot 9 \pm 6 \cdot 3$ \\
\hline Lysinc & & & \\
\hline $117 \cdot 5 \pm 26 \cdot 4$ & $201 \cdot 6 \pm 10 \cdot 4$ & $232 \cdot 9 \pm 12 \cdot 7$ & $191 \cdot 6 \pm 10 \cdot(0$ \\
\hline Histidine & & & \\
\hline $82 \cdot 3 \pm 9 \cdot 4$ & $61 \cdot 0 \pm 6 \cdot 6$ & $68 \cdot 6 \pm 6 \cdot 7$ & $56 \cdot 5 \pm 4 \cdot 8$ \\
\hline Arginine & & & \\
\hline $34 \cdot 6 \pm 3 \cdot 2$ & $48 \cdot 2 \pm 3 \cdot 5$ & $66 \cdot 8 \pm 4 \cdot 1$ & $71 \cdot 2 \pm 4 \cdot 1$ \\
\hline ᄂ & & 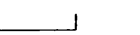 & \\
\hline & \llcorner & & 1 \\
\hline\llcorner & & 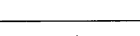 & 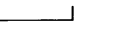 \\
\hline & \llcorner & - & \\
\hline
\end{tabular}

Table 2 Estimates of per cent loss and per cent loss per week (mean $\pm S E M)$ of total weight $(T W)$, lean body mass (LBM) and fat mass (FM) 41 patients with cancer weight loss and 12 patients with benign weight loss

\begin{tabular}{lcc}
\hline & Benign weight loss & Cancer weight loss \\
\hline$\%$ loss TW & $14 \cdot 40 \pm 2 \cdot 10$ & $15 \cdot 10 \pm 1 \cdot 60$ \\
$\%$ loss LBM & $7 \cdot 80 \pm 2 \cdot 40$ & $8 \cdot 9(0 \pm 1 \cdot 30$ \\
$\%$ loss FM & $34 \cdot 90 \pm 4 \cdot 40$ & $30 \cdot 40 \pm 2 \cdot 70$ \\
\hline$\%$ loss TW/weck & $0 \cdot 78 \pm(0 \cdot 14$ & $0 \cdot 95 \pm 0 \cdot 14$ \\
$\%$ loss LBM $/$ week & $0 \cdot 34 \pm(0 \cdot(9)$ & $0 \cdot 54 \pm 0 \cdot(08$ \\
$\%$ loss $\mathrm{FM} /$ week & $2 \cdot 01 \pm(0 \cdot 42$ & $1 \cdot 98 \pm 0 \cdot 28$ \\
\hline
\end{tabular}
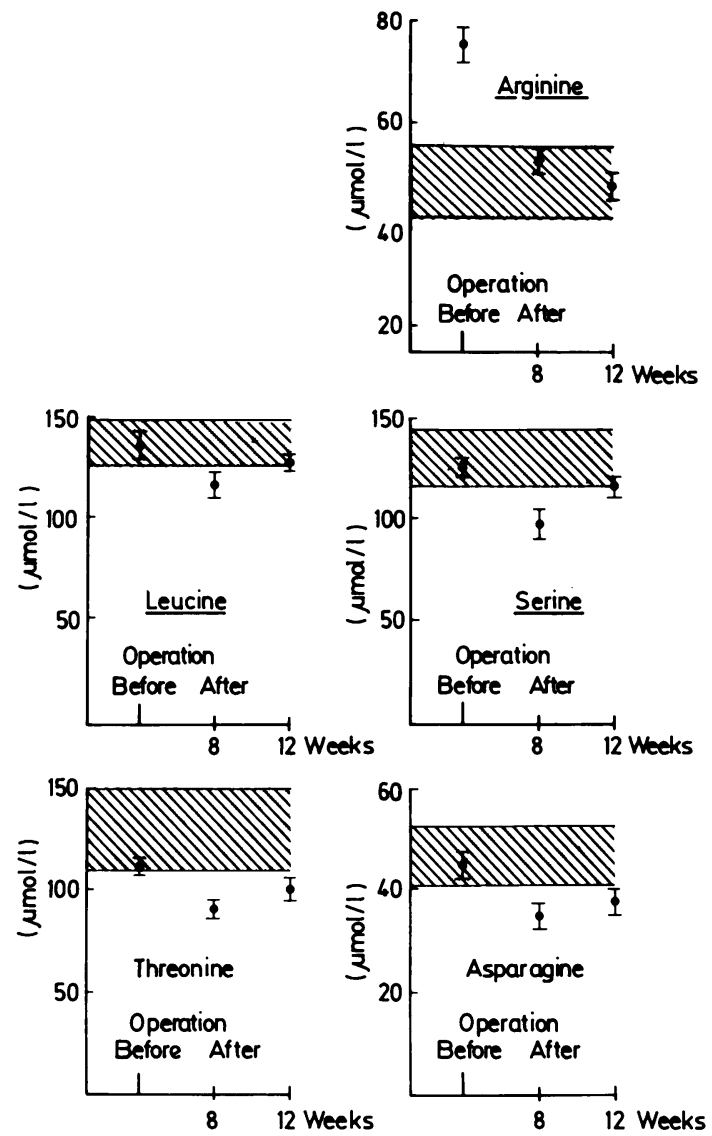

Fig. 1 Plasma amino acid concentration (umol/l, mean $\pm S E M)$ in 16 patients with cancer before, eight and 12 weeks after removing the primary tumour (shaded area represents $\pm 95 \%$ confidence limits from the mean of control patients). 
in these patients did not appear related to the amount of weight loss.

In 16 patients studied eight weeks after the removal of the primary tumour, there was a significant fall in the concentration of the amino acids arginine, serine, asparagine, leucine, and threonine when compared with pre-operative levels in the same patients $(\mathrm{p}<0.05$ Wilcoxon's signed rank test) (Fig. 1). When restudied 12 weeks after operation, the plasma concentration of arginine (48.6 44.4 $\mu \mathrm{mol} / \mathrm{l})$ was significantly lower than the pre-operative level $(76.4 \pm 7.5 \mu \mathrm{mol} / \mathrm{l})(\mathrm{p}<0.05)$. There was no significant difference between the concentration of threonine, serine, asparagine, and leucine 12 weeks after operation when compared with pre-operative values measured in the same patients.

Figure 2 shows the significant changes in amino acid concentration that occurred in six patients with pyloric stenosis when studied eight and 12 weeks after corrective surgery. Although the concentration of amino acids measured eight weeks after corrective surgery was not significantly different from preoperative values, when restudied 12 weeks after operation the concentration of the amino acids

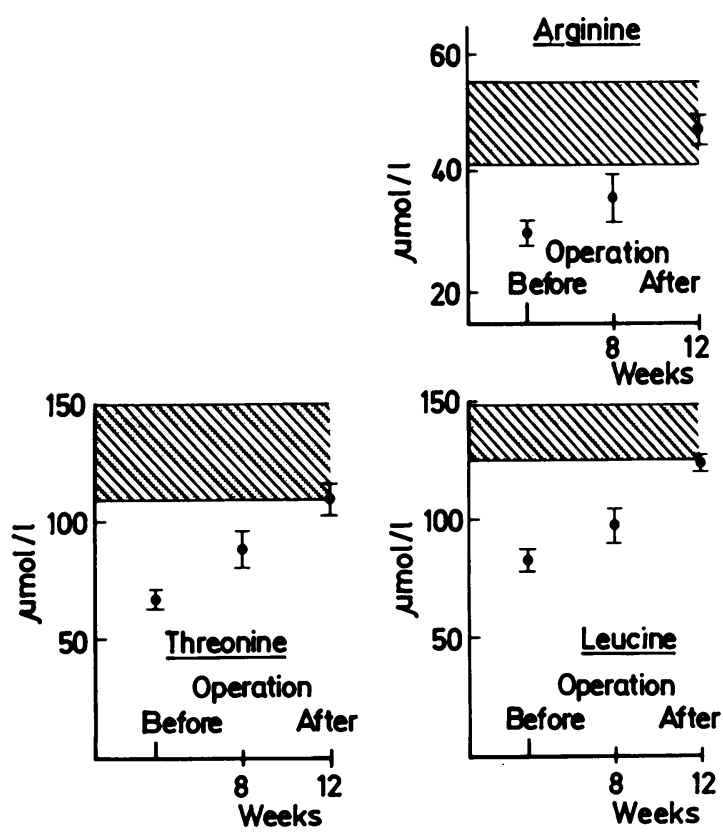

Fig. 2 Plasma amino acid concentration ( $\mu \mathrm{mol} / \mathrm{l}$, mean $\pm S E M)$ in six patients with pyloric stenosis before, eight and 12 weeks after corrective surgery (shaded area represents $\pm 95 \%$ confidence limits from the mean of control patients). arginine $(46 \cdot 6 \pm 2 \cdot 7 \mu \mathrm{mol} / \mathrm{l})$, leucine $(124 \cdot 1 \pm 4 \cdot 6$ $\mu \mathrm{mol} / \mathrm{l})$ and threonine $(109.7 \pm 13 \mu \mathrm{mol} / \mathrm{l})$ was significantly greater than pre-operative levels of arginine $(30.3 \pm 2.0 \mu \mathrm{mol} / \mathrm{l}) \quad(\mathrm{p}<0.001)$, leucine $(84.3 \pm 8.9$ $\mu \mathrm{mol} / \mathrm{l})(\mathrm{p}<0.01)$ and threonine $(66.6 \pm 4.3 \mu \mathrm{mol} / \mathrm{l})$ $(\mathrm{p}<0.05)$ (paired $t$ test).

\section{Discussion}

The concentration of amino acids in the peripheral blood is the result of a balance between the release of amino acids into the circulation (mainly from muscle) and extraction by certain tissues (mainly the liver). Earlier studies have established patterns of amino acids in the peripheral blood typical for the normal subject and for patients with several disease states. These include brief and prolonged starvation, ${ }^{4}$ surgical trauma ${ }^{5}$ and sepsis. ${ }^{6}$

Although the cancer patient is invariably anorexic, Clarke et al ${ }^{1}$ showed that such patients had different amino acid patterns from patients who were malnourished for other reasons. By studying arteriovenous differences in concentration of amino acids across the forearm in these patients, it was suggested that there existed a normal peripheral nitrogen conservation, but an enhanced glucogenic state reducing glucose precursor amino acids in the peripheral blood. Heim et $a l^{\prime}$ similarly studied the concentration of amino acids in the peripheral blood of patients with a variety of tumours, and reported abnormalities in patients with different types of tumour. Patients with gastrointestinal tumours had low levels of branched chain amino acids, those with breast cancers had an increased alanine and reduced leucine, and those with malignant lymphomas were characterised by low valine and tryptophan concentrations.

In the present study the concentration of the majority of amino acids in the blood of patients who had lost weight was similar to the pattern typically seen in patients with chronic malnutrition. ${ }^{4}$ The concentration of the amino acid arginine was, however, raised in patients with gastrointestinal cancer, and this was in contrast with the low levels of arginine measured in patients with benign disease. When the tumour was removed the concentration returned to normal levels. It would appear, therefore, that the raised levels of arginine in the blood of these patients was due to the presence of the primary tumour.

This abnormality is difficult to explain; the other urea cycle amino acids were normal and no patient had a raised blood urea. Arginine levels have been reported as being low in starvation ${ }^{4}$ in bacteraemia ${ }^{8}$ and in sepsis. ${ }^{6} \mathrm{~A}$ transient rise is seen after refeeding severely malnourished patients, ${ }^{4}$ but this is unlikely 
to have been the mechanism in the patients in this study. There is evidence to suggest that arginine stimulates tumour growth, ${ }^{9}{ }^{10}$ and the action of the enzyme arginase has been reported to be very high in tumours of non-hepatic tissue. " Attempts have been made to use arginase as a cytotoxic agent to lower the level of arginine in tissues and to inhibit tumour growth. ${ }^{12}$ More recently Currie ${ }^{13}$ showed that macrophages killed tumour cells in vitro by releasing arginase, and that the cytotoxic activity could be prevented by the addition of arginine.

These observations are of obvious interest, but a discussion as to the role of arginase and arginine in the patients studied in this investigation must remain speculative. The results of this study do suggest, however, that arginine metabolism in patients with cancer of the gastrointestinal tract merits further study.

\section{References}

1 Clarke EF, Lewis AM, Waterhouse C. Peripheral amino acid levels in patients with cancer. Cancer 1978; 42: 2909-13.

2 Goode AW. Measurements of body cell mass and its clinical applications. University of Newcastle-uponTyne: MD Thesis, 1978.

3 Goode AW, Hawkins $\mathrm{T}$. The use of ${ }^{41} \mathrm{~K}$ counting and its relationship to other estimates of lean body mass.
In: Johnson IDA ed. Advances in parenteral nutrition. Lancaster: MTP Press Ltd, 1978: 557-70.

4 Smith SR, Pozefsky T, Chetri MK. Nitrogen and amino acid metabolism in adults with protein-calorie malnutrition. Metabolism 1974; 23: 603-18.

5 Dale G, Young G, Latner AL, Goode A, Tweedle D, Johnston IDA. The effect of surgical operations on venous plasma free amino acids. Surgery 1977; 81: 295-301.

6 Freud H, Atamain S, Holroyde J, et al. Plasma amino acids as predictors of the severity and outcome of sepsis. Ann Surg 1979; 190: 571-6.

7 Heim ME, Stalt U, Meisinger E. Arterial and venous plasma amino acids in untreated cancer patients. EORTC Symposium. Brussels Nutrition of the cancer patient. 1981.

8 Reznik SR, Slabospitskaya AT, Kachan AF, et al. Effect of bacteraemia on the content of free arginine in blood serum with gastroenteric tract disease. [English Abstract]. Mikrobiol Zh 1979; 41: 378-81.

9 Dahlig E. The role of arginine and arginase in tumours. Postepy Hig Med Dosw 1978; 32: 523-31.

10 Bach SJ, La snitzkil. Some aspects of the role of arginine and arginase in mouse carcinoma 63. Enzymologia 1947; 12: 198-205.

11 Bhide SV, D'Souza RA. Biochemical characterization of human tumours. Indian J Exp Biol 1977; 15: 483-5.

12 Bach SJ, Swaine D. The effect of arginase on the retardation of tumour growth. Br J Cancer 1965; 19: 379-86.

13 Currie GA. Activated macrophages kill tumour cells by releasing arginase. Nature 1978; 273: 758-9. 